\title{
A 100 MEV INJECTOR LINAC FOR THE SWISS LIGHT SOURCE SUPPLIED BY INDUSTRY
}

\author{
M. Peiniger, C. Piel, H. Vogel, P. vom Stein, ACCEL Instruments, Bergisch Gladbach, Germany
}

\section{Abstract}

A $100 \mathrm{MeV}$ 'turn-key' injector electron linac for the Swiss Light Source (SLS) is under construction at ACCEL Instruments. The system will be installed, commissioned and handed over to the SLS in late 1999, after a 18 month design and production period.

This paper will present the special needs of an injector for a third generation synchrotron light source and the two specific modes of operation for this linac. The specification of the system and a description of the design results as well as the planned technical realisation will be given.

\section{REQUIREMENTS FOR THE SLS INJECTOR SYSTEM}

A third generation synchrotron light source is equipped with several types of insertion devices such as wigglers, undulators and wavelength shifters.

These devices can be driven in several operation modes. To drive a Free Electron Laser for example a single bunch mode operation is required. This results in single and multi bunch operation modes, to fulfil the different needs of the users.

\subsection{General specification}

The SLS accelerating system will consist of a $100 \mathrm{MeV}$ Linac and a full energy booster. The general parameters [1] of the linac are listed in the following table 1:

Table 1: General Specifications

\begin{tabular}{|l|l|}
\hline RF frequency & $2.997921 \mathrm{GHz}$ \\
\hline Max. repetition rate & $10 \mathrm{~Hz}$ \\
\hline Energy & $100 \mathrm{MeV}$ \\
\hline
\end{tabular}

\subsection{Pulse modes}

Two modes of operation are foreseen. One single bunch mode $^{1}$ and one variable multi bunch mode. The multi bunch mode will cover the range on 50-500 bunches. To reduce the effect of beam loading the multi bunch mode will carry the same charge as the single bunch mode. The basic parameters of both modes are given in table 2 .

In addition the SLS layout foresees a top up injection mode, this mode will deliver a low current to the storage

${ }^{1}$ In this context the bucket length of the ring rf system defines the bunch length of $2 \mathrm{~ns}$ ring, to keep the mean current in the storage ring nearly constant.

Table 2: Operation Modes

\begin{tabular}{|l|c|c|}
\hline & $\begin{array}{c}\text { Short } \\
\text { Pulse }\end{array}$ & Long Pulse \\
\hline Pulse length & $1 \mathrm{~ns}$ & $100-1000 \mathrm{~ns}$ \\
\hline Pulse charge & $1.5 \mathrm{nC}$ & $1.5 \mathrm{nC}$ \\
\hline Emittance & $\begin{array}{c}50 \pi \mathrm{mm} \\
\mathrm{mrad}\end{array}$ & $\begin{array}{c}50 \pi \mathrm{mm} \\
\mathrm{mrad}\end{array}$ \\
\hline Energy & $100 \mathrm{MeV}$ & $100 \mathrm{MeV}$ \\
\hline$\Delta \mathrm{E} / \mathrm{E}$ & $0.5 \%$ & $0.5 \%$ \\
\hline
\end{tabular}

\section{LAYOUT OF THE SYSTEM}

The main components of the injector system are based on components which were developed for the S-Band Test Facility (SBTF) at DESY 2. Adopting these components for the special needs of the SLS project took place during the design phase.

To fulfil the requirements the system consists of three functional sections:

- The electron source

- The bunching section

- The accelerating structures
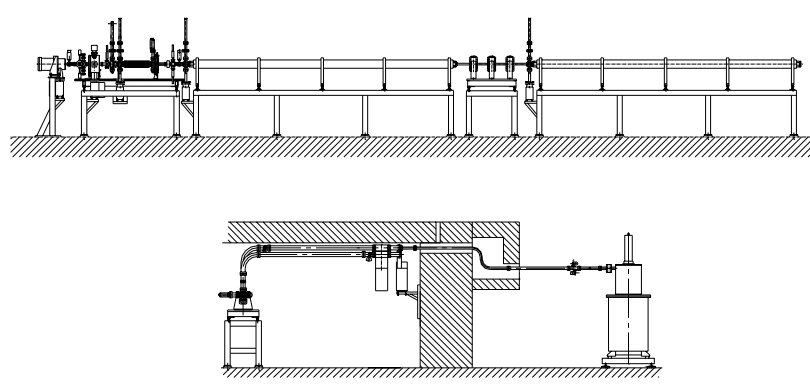

Figure 1: General Layout

\subsection{The electron source}

The electrons will be provided by a $90 \mathrm{kV}$ DC conventional electron source as shown in Figure 2. The electron emitter is a standard EIMAC cathode YU-171.

The pulser for the electron source comprises two systems, one for the single bunch and one for the multi bunch mode. In the single bunch mode a $1 \mathrm{~ns}$ pulse carrying $3 \mathrm{nC}$ will be sufficient to guarantee $1.5 \mathrm{nC}$ at the end of the Linac. The multi bunch mode will be modulated by the 499.652 MHz main ring rf, to insure a high bunch purity. 
The top up injection mode requires, that even the gun is capable of producing a low charge pulse. For that reason the pulse current can be varied by a factor of forty.

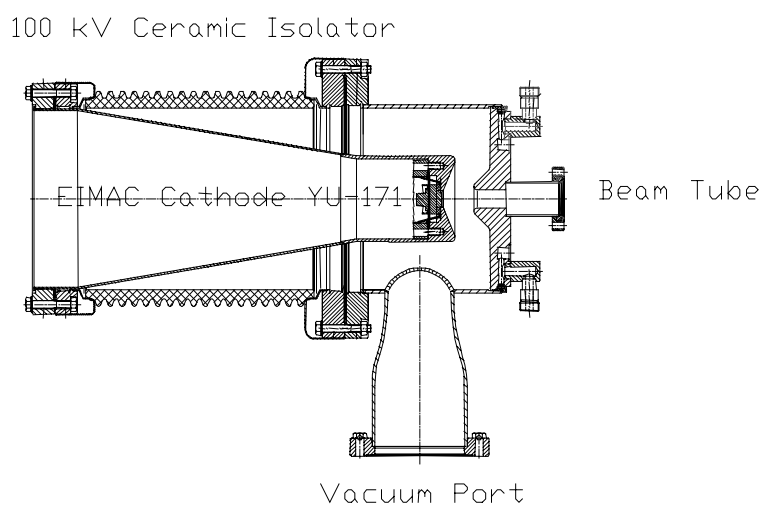

Figure 2: $90 \mathrm{kV}$ Electron Source

The basic parameters of the cathode are listed in the following table:

\begin{tabular}{|l|l|c|}
\hline \multicolumn{3}{|c|}{ Cathode YU-171 } \\
\hline Flange & $\mathrm{CF}$ & $23 / 4$ \\
\hline Cathode surface & $\mathrm{cm}^{2}$ & 1.0 \\
\hline Emission & $\mathrm{A}$ & 3 \\
\hline Cathode Radius & $\mathrm{mm}$ & 5,6 \\
\hline Cathode Typ & & Dispenser \\
\hline
\end{tabular}

\subsection{The bunching section}

The bunching section, as shown below, will consist of a $500 \mathrm{MHz}$ subharmonic prebuncher as shown in Figure 4, a 4 cell travelling wave buncher as sketched in Figure 5 and a 16 cell travelling wave buncher as shown in Figure 6. At the exit of the bunching section the beam will have an Energy of $3 \mathrm{MeV}$.

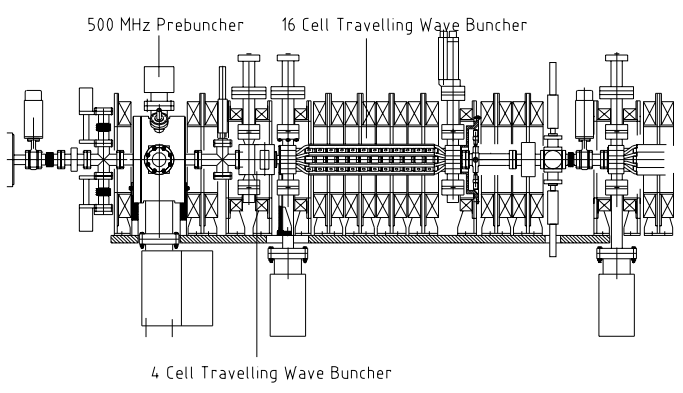

Figure 3: Bunching Section

To compensate space charge effects and rf defocusing the beam is focused by a solenoid magnetic field of up to 0.2 Tesla. This field will be produced by a set of more the 30 pancake coils, which guide the beam until it reaches an energy of $10 \mathrm{MeV}$.

\subsubsection{The $500 \mathrm{MHz}$ subharmonic Prebuncher}

The subharmonic prebuncher cavity is a standard nosecone cavity. The needed rf power will be fed into the system by a coaxial line.

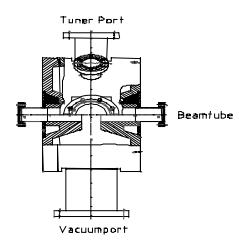

Figure 4: Layout of the $500 \mathrm{MHz}$ Prebuncher

The basic parameters of the buncher are given in the table below:

Table 3: Parameters of the Subharmonic Prebuncher

\begin{tabular}{|l|l|c|}
\hline Frequency & $\mathrm{MHz}$ & 500 \\
\hline Shuntimpedanz & $\mathrm{MW} / \mathrm{m}$ & 37 \\
\hline $\mathrm{Q}$ & & 28000 \\
\hline Amplitude Uo & {$[\mathrm{kV}]$} & 30 \\
\hline
\end{tabular}

\subsubsection{Travelling Wave Buncher System}

Two travelling wave bunchers will be used to insure a sufficient bunching in order to reach a high transmission rate with low energy spread.

The first $2 \pi / 3$ mode buncher consist out of four cells as shown in Figure 5. The layout had been done for $\beta=0.6$.
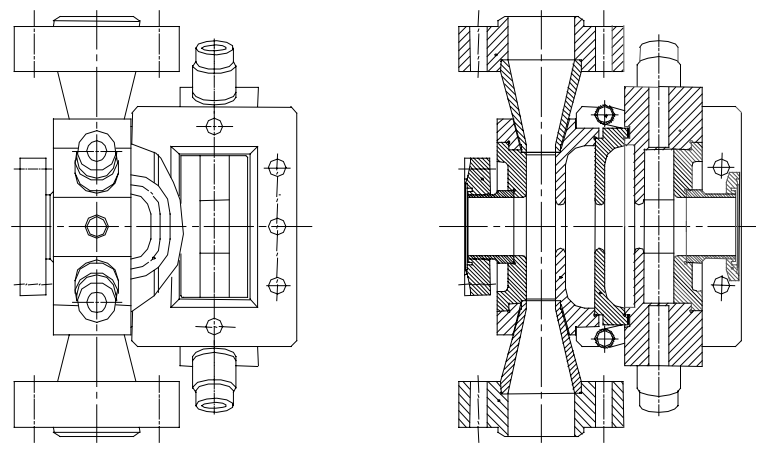

Figure 5: 4 Cell $2 \pi / 3$ mode Buncher

The second buncher, as shown in Figure 6, is optimised for $\beta=0.95$, consists of 16 cells and will be operated in the $8 \pi / 9$ mode.
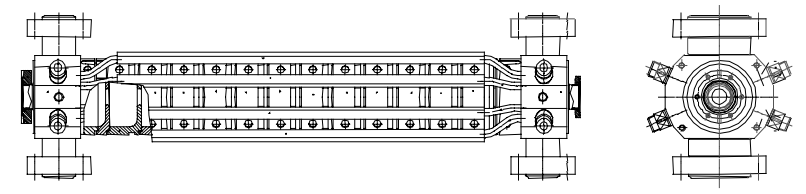

Figure 6: 16 Cell $8 \pi / 9$ Mode Buncher 


\subsection{Travelling Wave Accelerating Structure}

The accelerating structures are of DESY Linac II type.

Table 4: Parameters of the Linac II Structures

\begin{tabular}{|l|c|c|}
\hline length & $\mathrm{m}$ & 5.2 \\
\hline attenuation & Neper & 0.5 \\
\hline group velocity & \% of c & $3.3-1.2$ \\
\hline filling time & $\mathrm{ns}$ & 750 \\
\hline shunt imped. & $\mathrm{M} \Omega / \mathrm{m}$ & $52-62$ \\
\hline number of cells & & 156 \\
\hline
\end{tabular}

\section{DESIGN RESULTS}

To insure the performance of the system ACCEL carried out simulation calculations for the main components as electron source and bunching system.

The bunching section was optimised for the two different modes mentioned above.

The subharmonic prebuncher will focus more than $80 \%$ of the particles into one $3 \mathrm{GHz}$ bucket, for this a gap voltage of $30 \mathrm{kV}$ is needed.

When the beam enters the second travelling wave buncher more than $50 \%$ of the particles will populate $20^{\circ}$ of the central $3 \mathrm{GHz}$ bucket. The average energy is about 400 $\mathrm{keV}$.

Before entering the first accelerating structure $80 \%$ of the particles will be found in $20^{\circ}$ of the central bucket at an energy of about $3 \mathrm{MeV}$.

After passing two accelerating structures of the Linac II DESY type, which will be powered by moderate $18 \mathrm{MW}$, the beam will have reached $100 \mathrm{MeV}$. An overall transmission of $96 \%$ is designed. The bunching efficiency insures that more then $85 \%$ of those particles are within the energy spread acceptance of the booster which will be $+/-1.5 \%$.

\section{CONCLUSION}

This paper summarises the beam requirements of the injector linac for the $3^{\text {rd }}$ generation light source SLS. It is shown that a Linac with proven and reliable technology can fulfil these needs. The linac components and the design results are presented, showing that the requirements can be reached.

\section{ACKNOWLEDGEMENTS}

ACCEL Instruments want to use this opportunity to thank DESY for their co-operation in all parts of this project. The DESY experts always helped us with their expertise and discussions.
Beside DESY we also want to thank the SLS staff at PSI for their open and co-operative acting.

\section{REFERENCES}

[1] Specification for the ELECTRON PRE-INJECTOR LINAC for the SWISS LIGHT SOURCE, SLS SPEC03/RL02

[2] R. Brinkmann, Conceptual Design of a $500 \mathrm{GeV} \mathrm{e}^{+} \mathrm{e}$ Linear Collider, DESY 1997-048 